\title{
INFLUENCE OF INFILL DESIGN ON COMPRESSIVE AND Flexural MECHANical Properties of FDM PRINTED PLA MATERIAL
}

\author{
Damir Hodzic \& Adi Pandzic
}
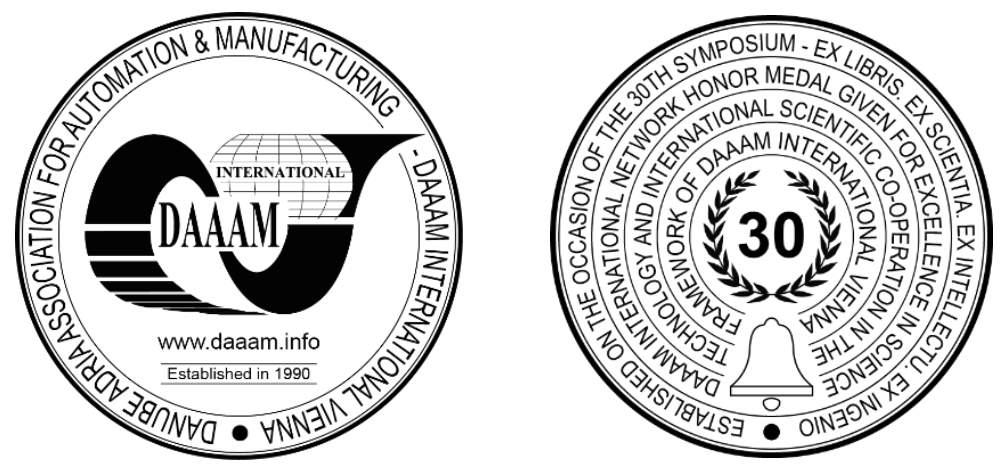

This Publication has to be referred as: Hodzic, D[amir] \& Pandzic, A[di] (2021). Influence of Infill Design on Compressive and Flexural Mechanical Properties of FDM Printed PLA Material, Proceedings of the 32nd DAAAM International Symposium, pp.0191-0199, B. Katalinic (Ed.), Published by DAAAM International, ISBN 978-3-90273433-4, ISSN 1726-9679, Vienna, Austria

DOI: $10.2507 / 32$ nd.daaam.proceedings.029

\begin{abstract}
Today, one of the fastest growing manufacturing technologies is certainly additive manufacturing, where there are several different product manufacturing processes, and one of the most famous is FDM 3D printing process. From literature review, it can be concluded that many parameters affect the final mechanical properties of FDM printed materials. Also, one of the great advantages provided by this technology is the production of product materials with an infill structure, which brings several advantages such as: reduced time of production, reduced material consumption, lower product weight and generally more economical production. The aim of this study is to analyse the influence of infill design on the compressive and flexural properties of FDM printed material. In particular, the influence of infill pattern and density for PLA FDM printed material was analysed. Based on the results of the statistical analyses, it can be concluded that the infill pattern and density affect the compressive and flexural strength and modulus of PLA FDM printed material.
\end{abstract}

Keywords: PLA material; FDM; Infill design; Material properties; 3D printing

\section{Introduction}

In general, additive manufacturing (AM), known as 3D printing, is defined as the novel technology used to produce the 3D/4D parts from a CAD model by adding layers of material bottom-up of various types of materials such as polymers, ceramics and composites. Fused deposition modelling (FDM) is one of AM technology that has experienced a great increase since it was presented on the market [1], [2], [3]. Also, one of the most well-known AM technologies is FDM, and it can be said, mostly due to the relatively low cost of the devices and materials used for production. In addition to the relatively low cost, FDM has other advantages presented below (Fig. 1) [4], [5], [6].

This technology finds its applications in education, research and many fields of engineering and industry, such as automotive products, aircraft, medical implants, dental and more. Also it is very popular in maker and start-up hubs, and changed the standard way of developing prototypes and products [7]. 


\begin{tabular}{|l|}
\hline \multicolumn{1}{c|}{ FDM technology advantages } \\
Complex geometry fabrication \\
Product material with infill structure \\
Easy aplication \\
Aast production of small series products \\
Rapid prototyping \\
\hline
\end{tabular}

Fig. 1. FDM technology advantages over traditional manufacturing production

FDM technology belongs to the group of AM processes that, in general, uses thermoplastic polymers, but in today's market there are FDM machines that also makes products from metallic materials [8]. In this process, the material is melted in a liquid state in a printer head (extruder) and then deposited through a nozzle that traces the parts cross sectional geometry to create 3D object (product, part) on printer build platform directly from a CAD model (Fig. 2) [7].

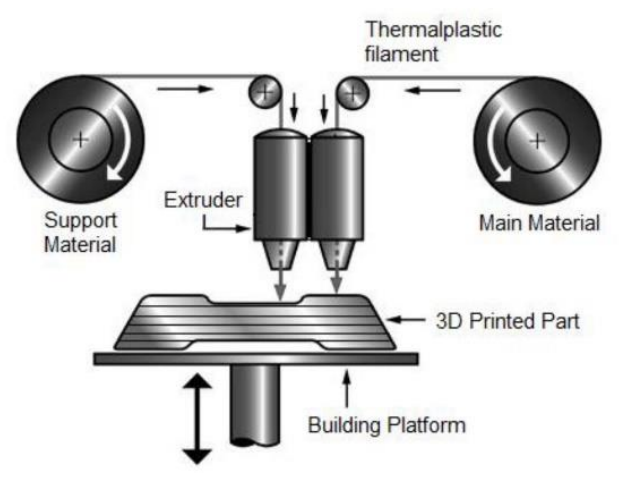

Fig. 2. Basics of FDM 3D printing process [9]

FDM 3D printer uses a CAD model for rapid prototyping process. The 3D model from CAD software, is converted to stereo lithography (.STL) format and after that, using "slicer" software, user is creating G-code for 3D printer [10]. Despite the number of advantages offered by these technologies, designers, when designing new products, must adapt the design of their product in order to take full advantage of these technologies. In addition to product design, the properties of FDMproduced parts significantly depend on the processing parameters. These parameters include layer height, nozzle temperature, nozzle diameter, air gap, build direction, print orientation, extrusion width, raster orientation, raster angle, infill pattern, infill density, infill angle, raster overlap and more [11], [12]. One of the benefits of FDM technology is the ability to fabricate the product material with an infill structure. Product material with infill structure provides several advantages (Fig. 3) such as reduced time of production, reduced material consumption, lower product weight and generally more economical production [1], [13], [14].

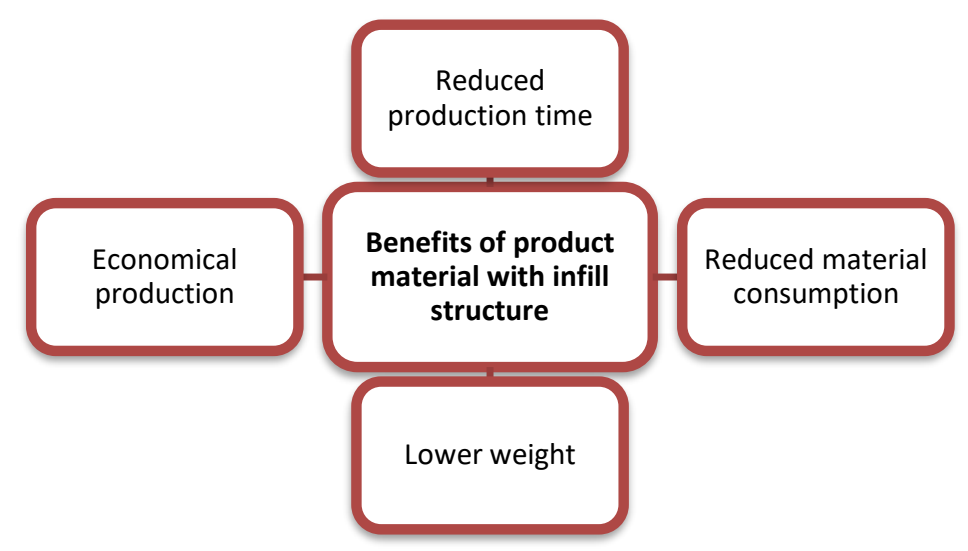

Fig. 3. Benefits of product material with infill structure 
A review of the above mentioned literature, as well as the study [15], shows the direct impact of infill design on the mechanical properties of FDM printed material. The focus of this research paper was to study the effect of infill pattern and density on compressive and flexural mechanical properties of PLA FDM printed material. Five different infill patterns, with variation of infill density, were analysed and compared with samples with $100 \%$ infill density. All results are analysed using statistical methods and presented in further text. Also, the literature review shows that the mechanical properties of printed materials are influenced by the material colour [3], the manufacturer (brand) of the material [4] as well as the model of the 3D printer [16]. In order to reduce the influencing factors on the results, for each test the samples were made on the same 3D printer, from materials of one manufacturer as well as the same colour.

\section{Research methodology}

Methodology of the experimental part of this research is presented on Fig. 4, where the goal was to analyse the influence of the infill pattern and density on the compressive and flexural properties of FDM printed PLA material.

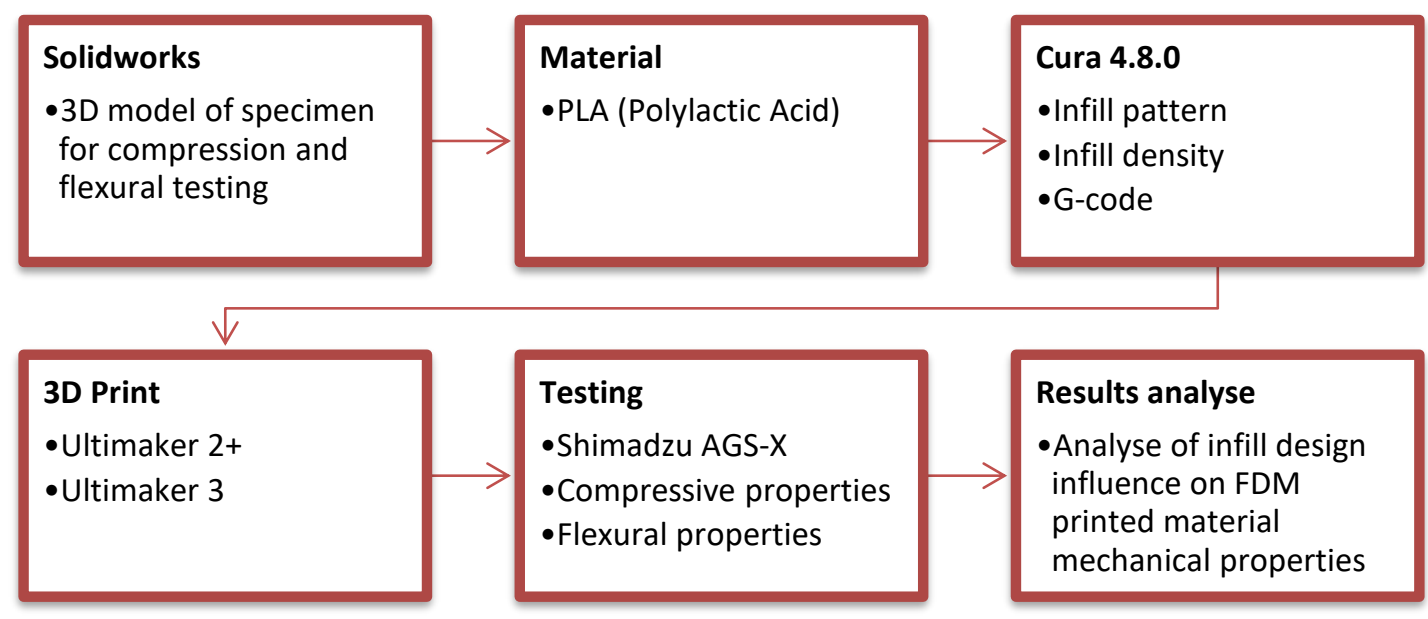

Fig. 4. Methodology of research experiment

Using Solidwors CAD software, 3D models of testing specimens were created, where the specimen for compression testing were designed according to ASTM D695 and for the flexural testing according to the EN ISO 178 standard (Fig. 5). As there are still no standards for FDM materials testing, but also for materials in additive technologies in general, material testing in this study is based on these standards, as can be seen in other research papers.
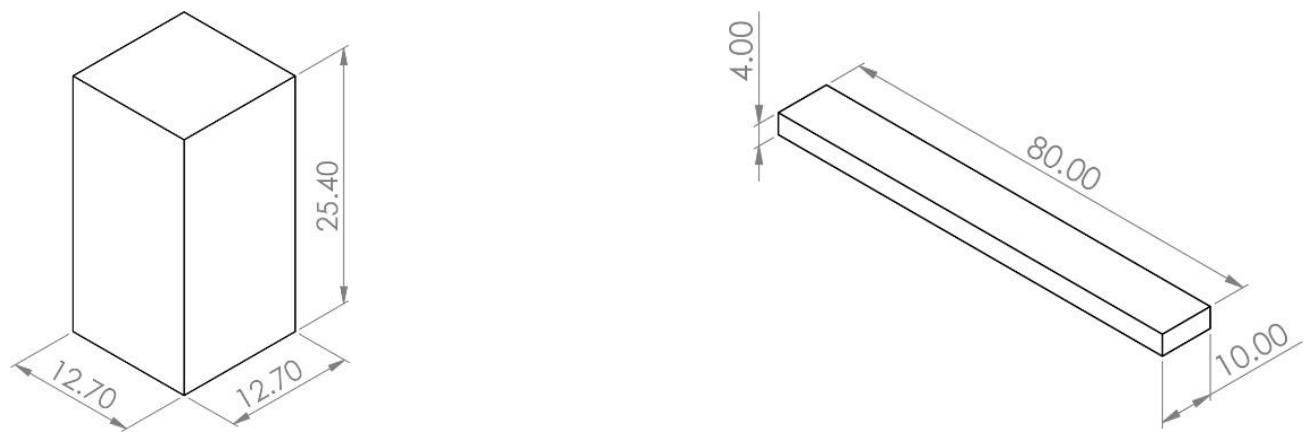

Fig. 5. Compressive (ASTM D695) and flexural (EN ISO 178) testing specimen

In this study, significantly researched and widely used PLA (supplied by 3D Republika) material was examined. PLA is from group of aliphatic polyesters, nontoxic and biodegradable material. A biopolymer prepared from corn, sugarcane, with relatively good mechanical properties and its major drawbacks include brittleness and low thermal stability [4], [6], [17]. As meintoined before, in general, FDM printed materials properties depends on 3D printing parameters and for this experiment all specimens are printed with same 3D printing parameters defined by default Ultimaker printing profile "Normal 0,15mm". Specimens and 3D printing parameters are prepared for printing using Cura 4.8.0 slicer and all specimens are printed with Ultimaker FDM 3D printers.

In slicer Cura, it is possible to choose 13 different infill patterns, but for this study, five different patterns were analysed (Fig. 6.), as follows: concentric (CO), grid (GR), gyroid (GY), octet (OC) and triangle (TR), and for each pattern the density was varied $(20 \%, 40 \%, 60 \%, 80 \%$ and $100 \%)$. 


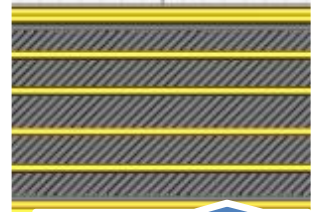

Concentric
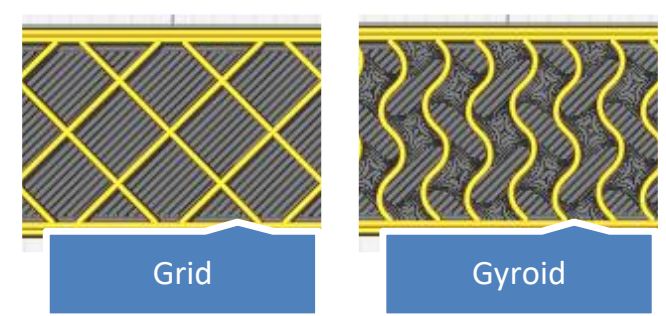

Gyroid

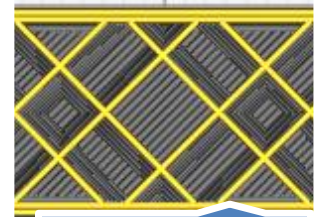

Octet

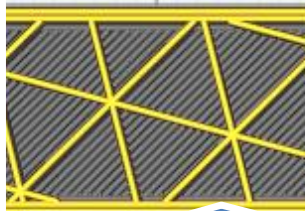

Triangle

Fig. 6. Five different infill patterns used for testing

From slice Cura, g-code with printing details and parameters is transferred to 3D printers. All specimens for compressive testing are printed with Ultimaker 2+ and for flexural testing with Ultimaker 3. Compressive (ASTM D695) and flexural (EN ISO 178) testing of printed samples were performed on a Shimadzu AGS-X universal testing machine (Fig. 7), where strain rate was $5 \mathrm{~mm} / \mathrm{min}$. For every test, five specimens are tested. The results and Hooks diagrams are recorded and collected with Shimadzu Trapezium X software, and in further text statistical analyses are presented.
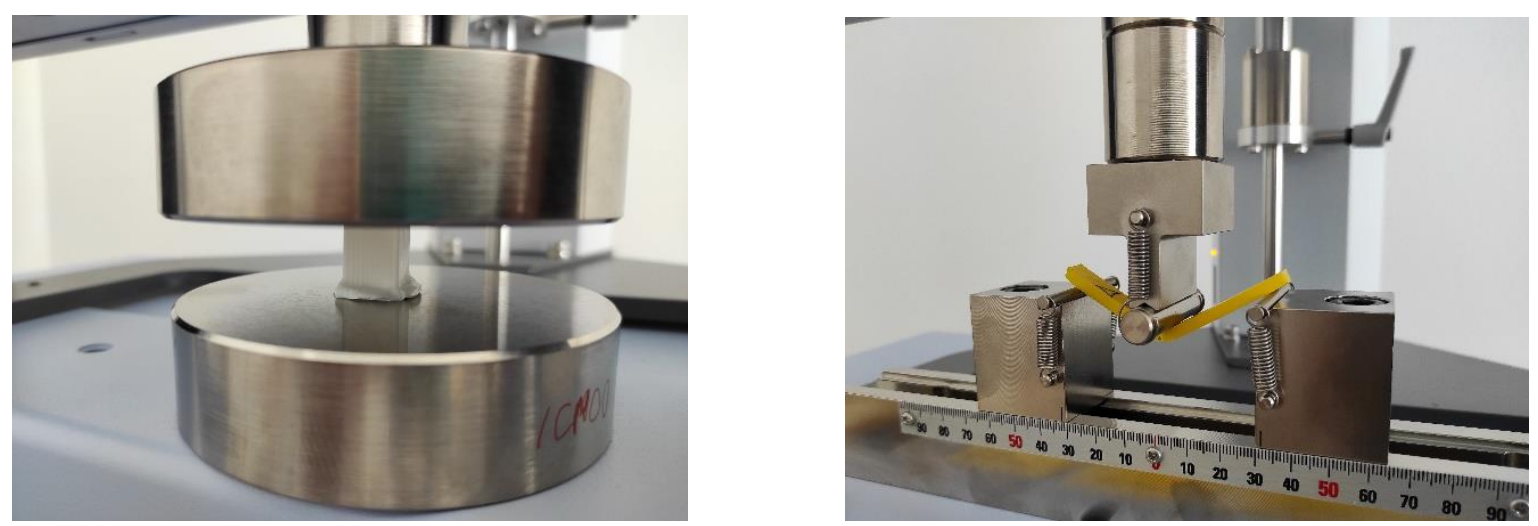

Fig. 7. Compressive (left) and flexural (right) testing on Shimadzu AGS-X testing machine

\section{Results and discussion}

After analysing the obtained data of compressive and flexural material testing, the results with discussion are presented below. What has been analysed is whether the infill pattern and density affect the compressive and flexural properties of the FDM printed PLA material with infill structure. Compressive and flexural strength as well as young modulus were analysed from the material properties. A total of five different infill patterns were analysed, where different infill density was varied for each pattern $(20 \%, 40 \%, 60 \%$ and $80 \%)$. What should be noted is that the strength results obtained by the test are values for the "full" cross section of the material, but as the aim of the research is to see percentage differences in mechanical properties, so this will not affect the final results.

Compressive and flexural stress-strain diagrams for PLA FDM 3D printed material with "Triangle" infill structure with different infill density are presented on Fig. 8.
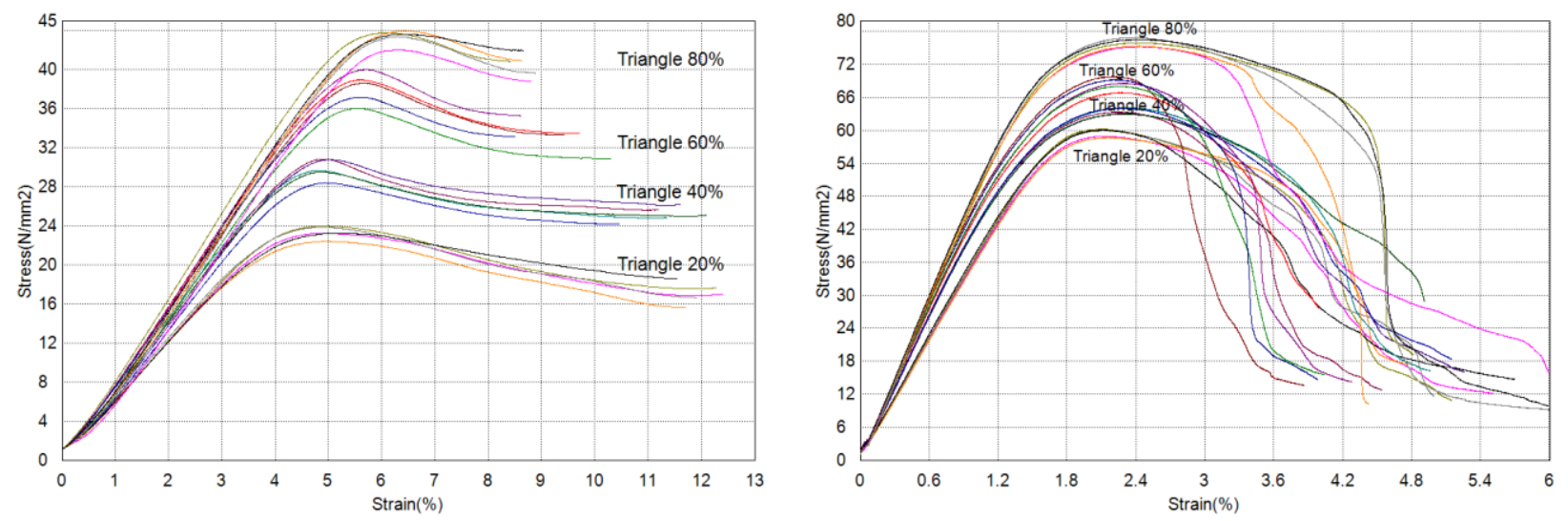

Fig. 8. Compressive (left) and flexural (right) stress - strain diagrams for "Triangle" infill pattern with different infill density 
From Fig. 9. it can be seen that infill density have influence on compressive strength for every tested infill pattern, and for each pattern the compressive strength increases linearly with increasing infill density. Also, as expected, the highest values of compressive strength were obtained for an infill density of $80 \%$.

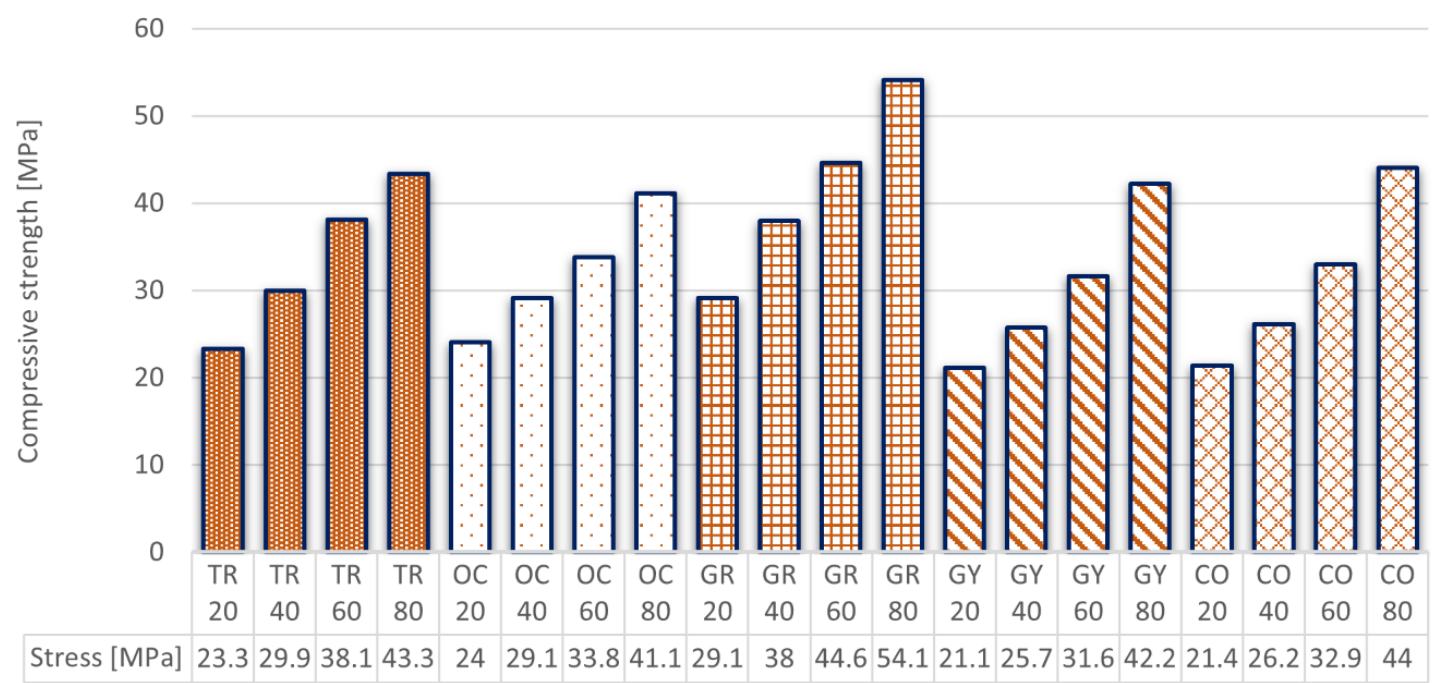

Fig. 9. Influence of infill density for five different infill patterns on compressive strength

The diagram below (Fig. 10) shows that in addition to the infill density, the infill pattern also has an effect on the compressive strength. In general, it can be observed that from five tested infill patterns, "Grid" pattern gives the highest values of compressive strength for all tested infill densities. It is interesting to see that the "Grid" pattern with density of $20 \%$ shows higher compressive strength than "GY" and "CO" patterns with density of $40 \%$, and the same value as the "OC" pattern. Also, the "Grid" pattern with $60 \%$ density gives a higher value of compressive strength than the "TR", "OC", "GY" and "CO" patterns with a density of $80 \%$.

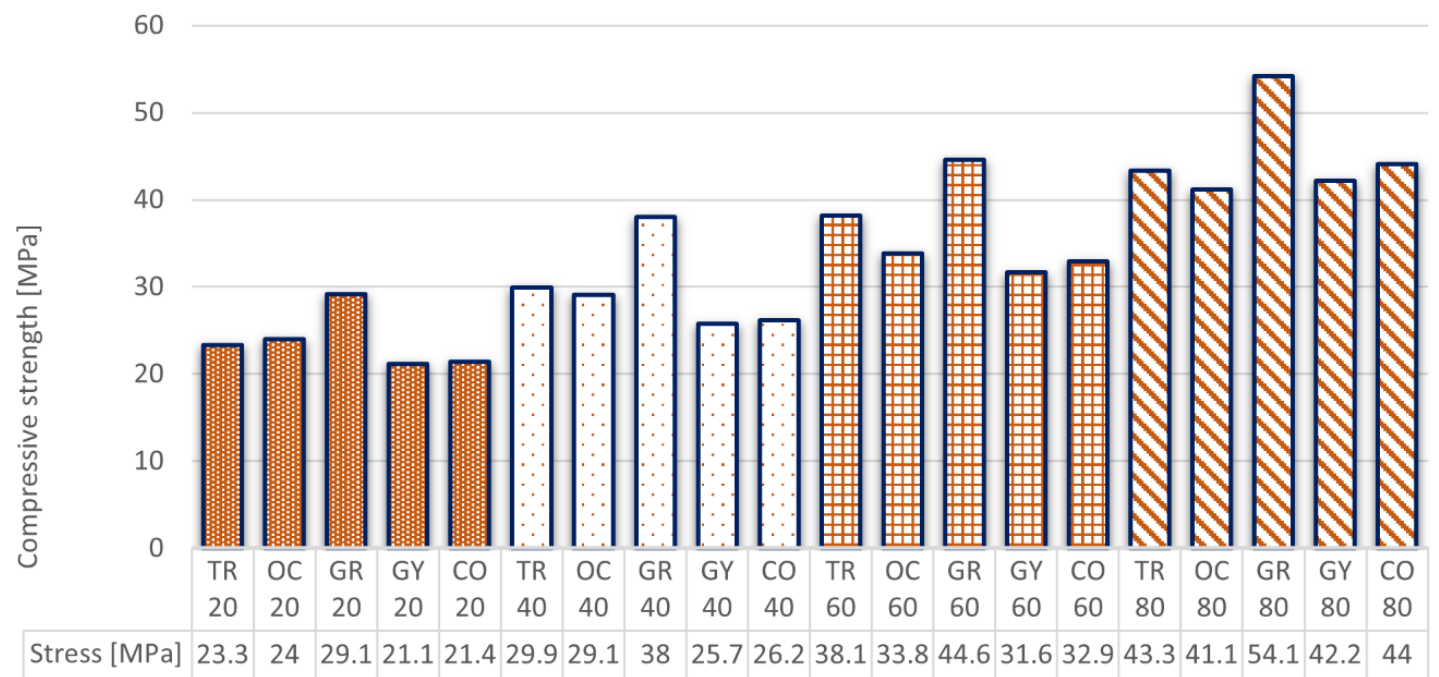

Fig. 10. Influence of infill pattern with different infill density on compressive strength

The diagram in Fig. 11. shows that the infill density also affects the compressive modulus, and generally for all five tested infill patterns a linear relationship between the infill density and the compressive modulus can be seen. In the case of "Triangle" and "Grid" patterns, it can be noticed that for infill densities of $60 \%$ and $80 \%$, relatively equal values of compression modulus are obtained, where the difference for "Triangle" pattern is about 3\% and for "Grid" pattern about $1,5 \%$.

Influence of infill pattern with different infill density on compressive modulus is presented on diagram bellow (Fig, 12). From the diagram it can be concluded that the infill pattern affects the compressive modulus, where for infill density of $20 \%, 40 \%$ and $60 \%$, depending on the infill pattern, compressive modulus differs up to $15 \%$. While for a infill density of $80 \%$, the compressive modulus for the "Gyroid" pattern is lower by $7 \%$ compared to other patterns that have relatively the same compressive modulus value. 


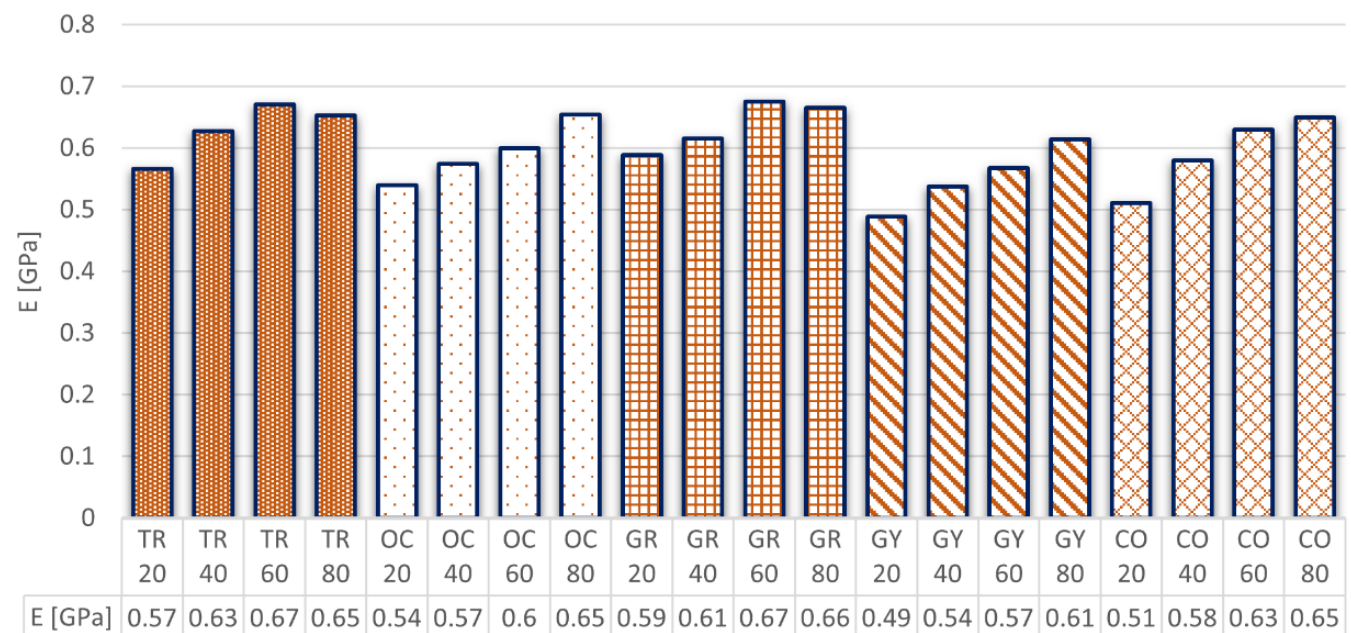

Fig. 11. Influence of infill density for five different infill patterns on compressive modulus, E [GPa]

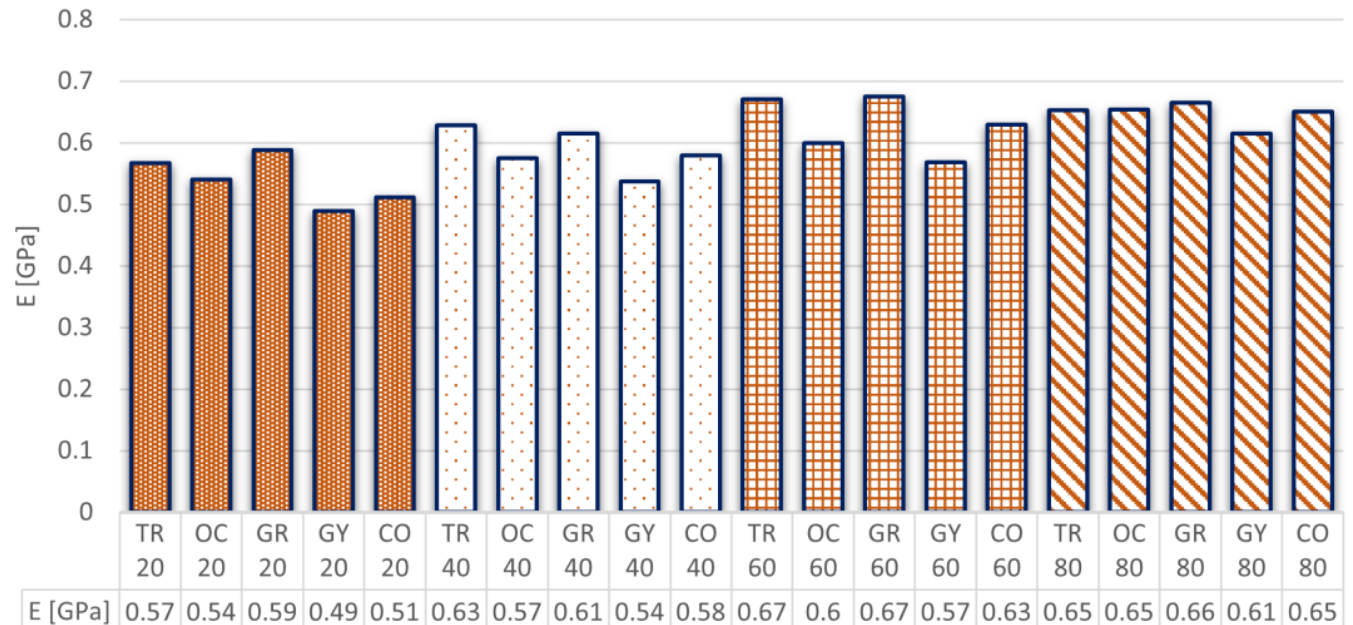

Fig. 12. Influence of infill pattern with different infill density on compressive modulus, E [GPa]

The obtained results of compressive mechanical properties of FDM 3D printed PLA material with infill structure could not be compared with the results of samples with $100 \%$ infill density, because the testing machine has a maximum force of $10 \mathrm{kN}$, and samples of PLA material with $100 \%$ infill density require higher force at compressive tests.

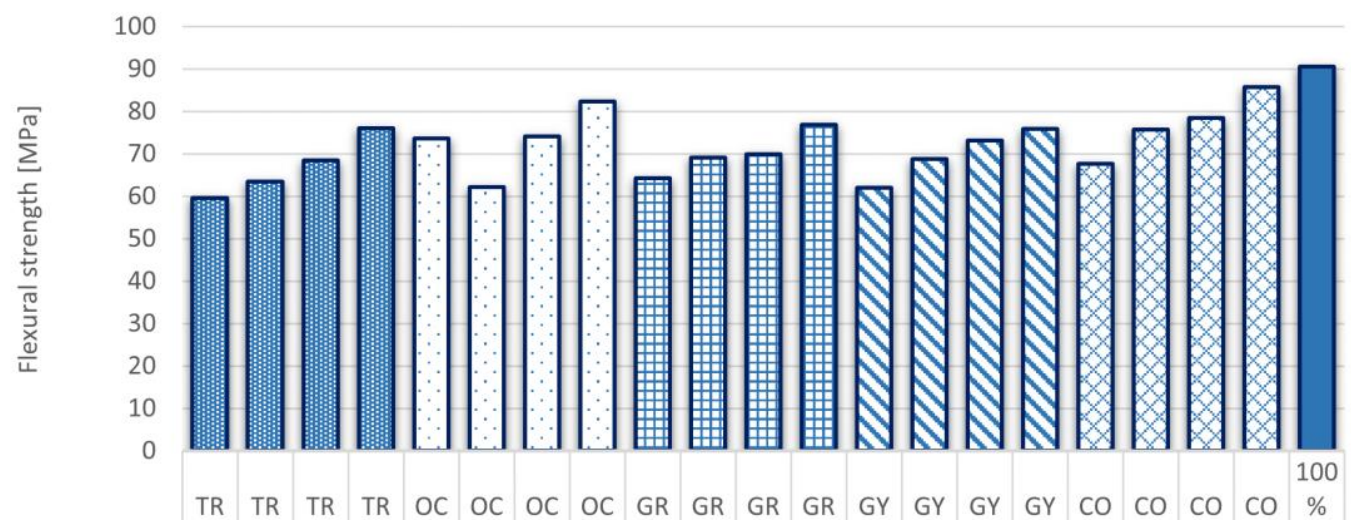

\begin{tabular}{|l|l|l|l|l|l|l|l|l|l|l|l|l|l|l|l|l|l|l|l|l|}
20 & 40 & 60 & 80 & 20 & 40 & 60 & 80 & 20 & 40 & 60 & 80 & 20 & 40 & 60 & 80 & 20 & 40 & 60 & 80 & Infil
\end{tabular}

Stress [MPa] $59.663 .568 .576 \quad 73.762 .274 .182 .464 .269 .169 .876 .862 .168 .773 .175 .867 .675 .678 .585 .790 .5$

Fig. 13. Influence of infill density for five different infill patterns on flexural strength 
From diagram above (Fig. 13) it can be seen that infill density have influence on flexural strength for every tested infill pattern, and for each pattern the flexural strength increases linearly with increasing infill density. Also, with the "Octet" infill pattern, it can be seen that an infill density of $20 \%$ gives a higher value of flexural strength, wich is not expected, so these measurements should certainly be repeated.

As expected, the highest values of flexural strength were obtained for an infill density of $80 \%$, and when they are compared with the flexural strength values for infill density of $100 \%$ the flexural strength varies from $5 \%$ to $17 \%$ depending on the shape of the infill.

The diagram from Fig. 14. shows that the infill pattern influences the flexural strength. If we exclude the results for the "Octet" pattern with infill density of $20 \%$ due to the previously mentioned reasons, it can be concluded that the "Concentric" pattern gives the highest values of flexural strength. What also can be concluded from the diagram is that "Concentric" pattern with density of $20 \%$ shows higher flexural strength than "TR" and "OC" patterns with density of $40 \%$. Also, the "Concentric" pattern with $60 \%$ density gives a higher value of flexural strength than the "TR", "GR" and "GY" patterns with a density of $80 \%$.

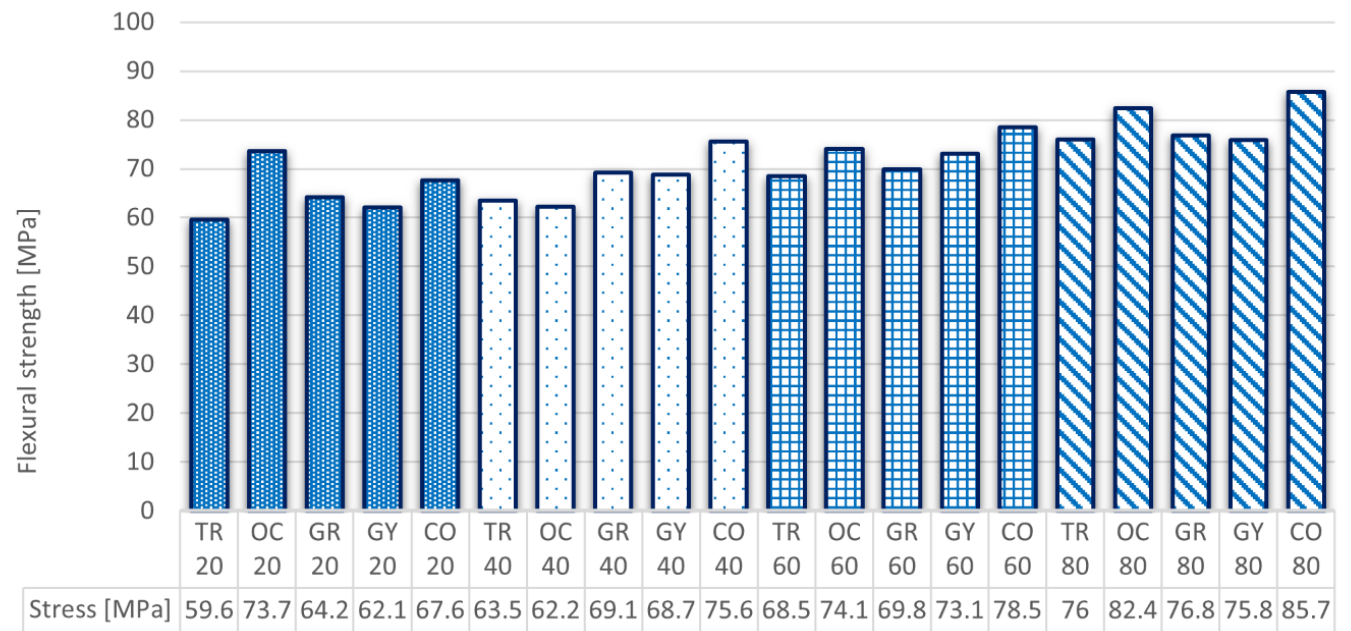

Fig. 14. Influence of infill pattern with different infill density on flexural strength

The diagram in Fig. 15. confirms the influence of infill density on flexural modulus, where the linear dependence of flexural modulus and infill density are also confirmed. It can be noticed that for the "Octet" and "Concentric" infill pattern with an infill density of $80 \%$, the flexural modulus value differs by $4 \%$ (for Octet) and $0,7 \%$ (for Concentric) compared to the test sample with $100 \%$ infill density.

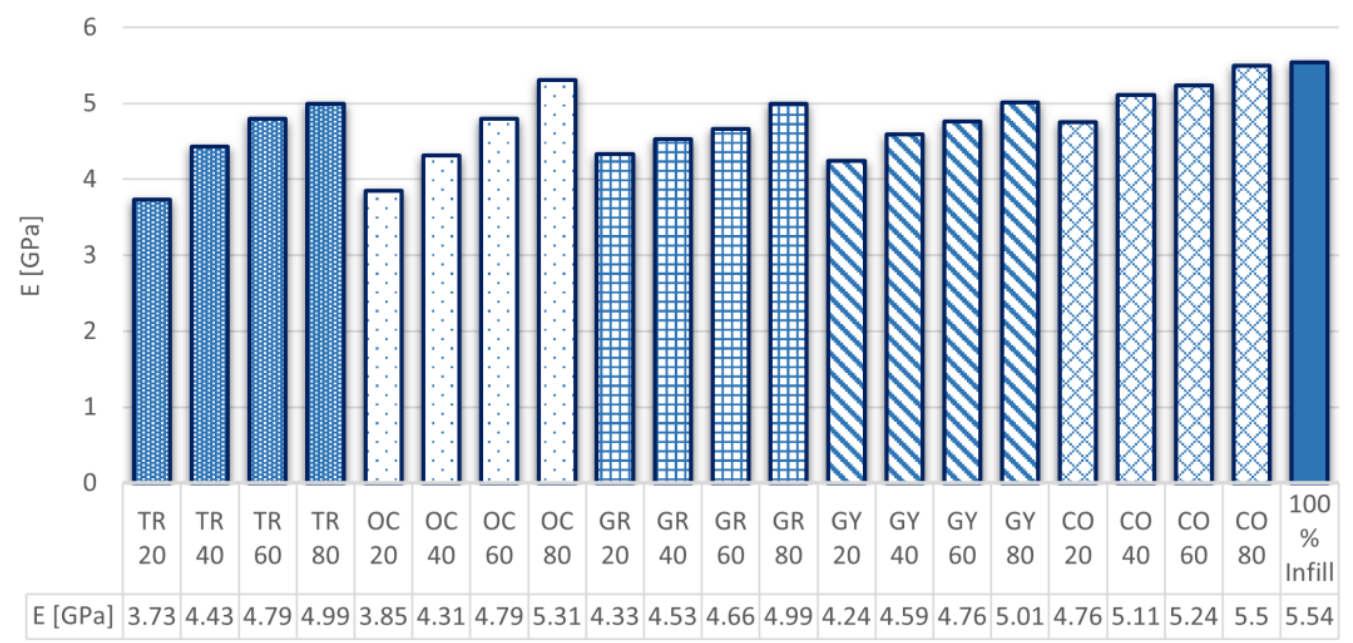

Fig. 15. Influence of infill density for five different infill patterns on flexural modulus, E [GPa]

The results of influence of infill pattern with different infill density on flexural modulus are presented on diagram bellow (Fig, 16). From the diagram it can be concluded that the infill pattern affects the flexural modulus, and depending on the infill pattern, for infill density of $20 \%$ differs up to $15 \%$, for infill density of $40 \%$ differs up to $17 \%$, for infill density of $60 \%$ differs up to $12 \%$ and for infill density of $80 \%$ differs up to $10 \%$. 


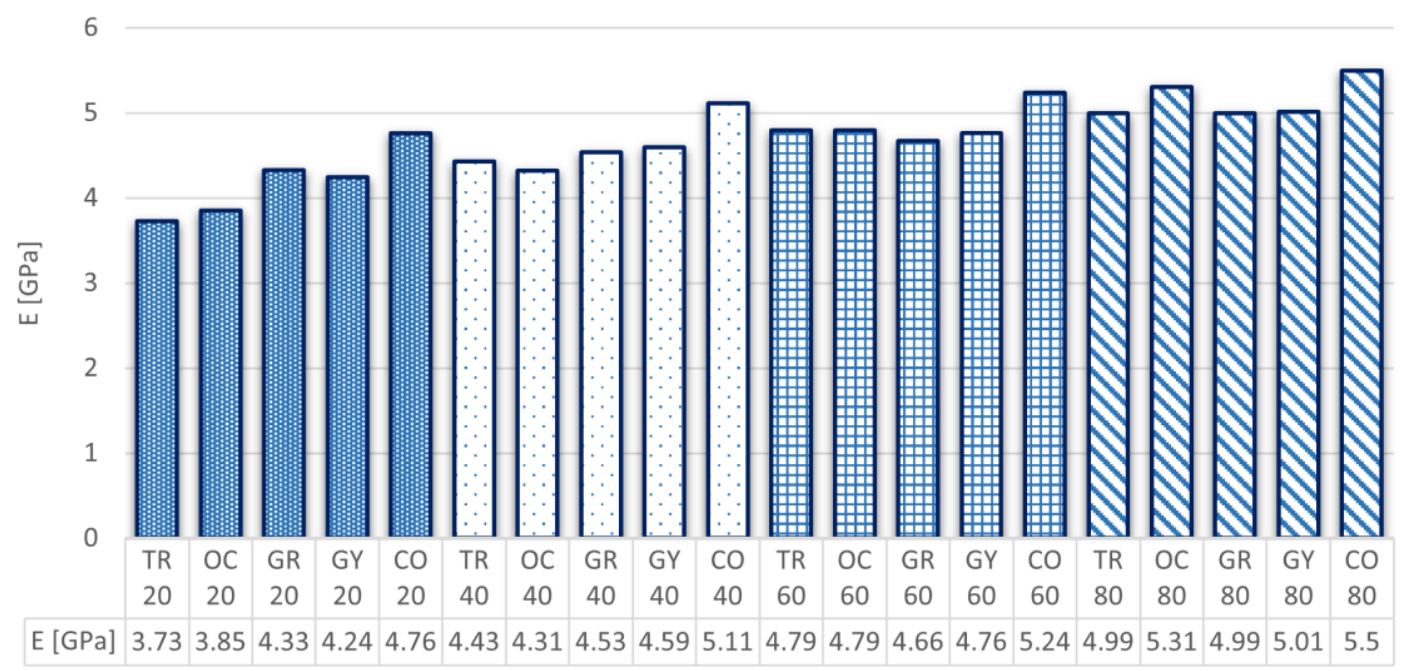

Fig. 16. Influence of infill pattern with different infill density on flexural modulus, E [GPa]

\section{Conclusion}

The experimental study presented in this research paper aims to present the influence of infill pattern and density on compressive and flexural mechanical properties of FDM printed PLA material. Five different infill patterns (Triangle, Octet, Grid, Gyroid and Concentric) with different infill densities (20\%, 40\%, 60\% and 80\%) were analysed. Of the mechanical properties, compressive and flexural strength as well as modulus of elasticity were analysed, and results obtained from this research conclude the followings:

- Infill density have influence on compressive strength for every tested infill pattern, and compressive strength increases linearly with infill density increase.

- Infill pattern influences the compressive strength. From five tested infill patterns, "Grid" pattern gives the highest values of compressive strength for all tested infill densities. The "Grid" pattern with density of $20 \%$ shows higher compressive strength than "GY" and "CO" patterns with density of $40 \%$, and the same value as the "OC" pattern. Also, the "Grid" pattern with $60 \%$ density gives a higher value of compressive strength than the "TR", "OC", "GY" and "CO" patterns with a density of $80 \%$.

- Infill density affects the compressive modulus, where for all five examined infill patterns a linear relationship between the infill density and the compressive modulus is shown. For "Triangle" and "Grid" patterns, with infill densities of $60 \%$ and $80 \%$, relatively equal values of compression modulus are obtained, where the difference for "Triangle" pattern is about $3 \%$ and for "Grid" pattern about $1,5 \%$.

- Infill pattern affects the compressive modulus, where for infill density of $20 \%, 40 \%$ and $60 \%$, depending on the infill pattern, compressive modulus differs up to $15 \%$. While for a infill density of $80 \%$, the compressive modulus for the "Gyroid" pattern is lower by 7\% compared to other patterns that have relatively the same compressive modulus value.

- Infill density have influence on flexural strength for every tested infill pattern, and for each pattern the flexural strength increases linearly with increasing infill density. Also, with the "Octet" infill pattern, an infill density of $20 \%$ gives a higher value of flexural strength, which is not expected, so these measurements should certainly be repeated.

- Infill pattern influences the flexural strength, and it can be concluded that the "Concentric" pattern gives the highest values of flexural strength. What also can be concluded from the results is that "Concentric" pattern with density of $20 \%$ shows higher flexural strength than "Triangle" and "Octet" patterns with density of $40 \%$. Also, the "Concentric" pattern with $60 \%$ density gives a higher value of flexural strength than the "Triangle", "Grid" and "Gyroid" patterns with a density of $80 \%$.

- Results confirms the linear influence of infill density on flexural modulus. It can be noticed that for the "Octet" and "Concentric" infill pattern with an infill density of $80 \%$, the flexural modulus value differs by $4 \%$ (for Octet) and $0,7 \%$ (for Concentric) compared to the test sample with $100 \%$ infill density.

- Infill pattern affects the flexural modulus, and depending on the infill pattern it differs from $10 \%$ to $17 \%$.

In general, the printed materials with an infill structure are the future of production, which provides a number of advantages. In this research, only one segment of the influence of infill design on the compressive and flexural mechanical properties of PLA material was performed. In order to better understand and describe the behaviour of printed materials with an infill structure, similar tests should be performed on other materials too in future research. Also, the influence of infill design should be examined in the other two build orientation, because in this paper only one build orientation was analysed. What else should be also done on the topic of material characterization, where the results of real strength values would be obtained, because in the case of materials with infill structure, the cross section is not solid. In future, research on obtaining models of materials for FEM/FEA analyses and more should be done. 


\section{Acknowledgments}

The authors would like to acknowledge the Ultimaker and 3D Republika companies for supporting this research with 3D printers and materials.

\section{References}

[1] Pandzic, A.; Hodzic, D. \& Milovanovic, A. (2019). Effect of Infill Type and Density on Tensile Properties of PLA Material for FDM Process, Proceedings of the 30th DAAAM Interational Symposium, pp.0545-0554, B. Katalinic (Ed.), Published by DAAAM International, ISBN 978-3-902734-22-8, ISSSN 1726-9679, Vienna, Austria, DOI: 10.2507/30th.daaam.proceedings.074

[2] Rahmatabadi, D.; Aminzadeh, A.; Aberoumand, M. \& Moradi M. (2021). Mechanical Characterization of Fused Deposition Modeling (FDM) 3D Printed Parts, In: Dave H.K., Davim J.P. (eds) Fused Deposition Modeling Based 3D Printing. Materials Forming, Machining and Tribology. Springer, Cham. DOI: 10.1007/978-3-030-68024-4_7

[3] Pandzic, A.; Hodzic, D. \& Milovanovic, A. (2019). Influence of Material Colour on Mechanical Properties of PLA Material in FDM Tecgnology, Proceedings of the 30th DAAAM Interational Symposium, pp.0555-0561, B. Katalinic (Ed.), Published by DAAAM International, ISBN 978-3-902734-22-8, ISSSN 1726-9679, Vienna, Austria, DOI:10.2507/30th.daaam.proceedings.075

[4] Hodzic, D.; Pandzic, A.; Hajro, I. \& Tasic, P. (2020). Strength Comparison of FDM 3D Printed PLA made By Different Manufacturers, TEM Journal, Vol. 9, No. 3, 2020, pp. 966-970., ISSN 2217-8390, DOI:10.18421/TEM9318

[5] Nuha, H. J. Al Hasan. (2020). The influence of an Infill Density, Percent on the Flexural Strength of the 3D, Key Engineering Materials, Vol. 870, pp. 73-80., ISSN 1662-9795, DOI: 10.4028/www.scientific.net/KEM.870.73

[6] Dey, A.; Hoffman, D. \& Yodo, N. (2019). Optimizing Multiple Process Parameters in Fused Deposition Modeling With Particle Swarm Optimization, International Journal on Interactive Design and Manufacturing, Vol. 14, pp. 393405, DOI: $10.1007 / \mathrm{s} 12008-019-00637-9$

[7] Farhad M. O.; TahseenFadhil A. \& Hind B. A. (2018). Influence of Process Parameters on Mechanical Properties and Printing Time of FDM PLA Printed Parts Using Design of Experiment. Journal of Engineering Research and Applications, Vol. 8, No. 7, (2018) pp. 65-69, ISSN: 2248-9622

[8] Hodzic, D.; Pandzic, A.; Hajro, I. \& Tasic, P. (2020). Strain Rate Influence on Mechanical Characteristics of FDM 3D printed Materials, Proceedings of the 31st DAAAM Interational Symposium, pp.0168-0175, B. Katalinic (Ed.), Published by DAAAM International, ISBN 978-3-902734-29-7, ISSN 1726-9679, Vienna, Austria, DOI:10.2507/31st.daaam.proceedings.022

[9] Huu, N. H.; Phuoe, D. P.; Huu, T. N. \& Thu, H. T. T. (2019). Optimization of the FDM Parameters to Improve The Compressive Strength of The PLA-Copper Based Products. IOP Conference Series: Materials Science and Engineering, 530 012001. DOI:10.1088/1757-899X/530/1/012001

[10] Shabana, S.; Santosh, R. V. N.; Vikram, K. A. \& Lakshmi, V. V. K. (2019). Evaluating the Mechanical Properties of Commonly Used 3D Printed ABS and PLA Polymers With Multi Layered Polymers. International Journal of Engineering and Advanced Technology, Vol. 8, No. 6, 2019, ISSN: 2249-8958, DOI: 10.35940/ijeat.F8646.088619

[11] Gebisa, A. W. \& Lemu, H. G. (2018). Investigation Effects of Fused-Deposition Modeling (FDM) Processing Parametes on Flexural Properties of ULTEM 9085 using Designed Experiment. Materials, Vol. 11, No. 4, DOI: $10.3390 / \mathrm{ma} 11040500$

[12] Akhoundi, B. \& Behravesh, A. H. (2019). Experimental Mechanics, Vol. 59, pp. 883-897, ISSN 0014-4851, DOI: $10.1007 / \mathrm{s} 11340-018-00467-\mathrm{y}$

[13] Habrman, M. (2019). Influence of the Infill on the Tensile Strength and the Economic Factors of 3D Printing, Proceedings of the 30th DAAAM Interational Symposium, pp.1056-1060, B. Katalinic (Ed.), Published by DAAAM International, ISBN 978-3-902734-22-8, ISSSN 1726-9679, Vienna, Austria, DOI: 10.2507/30th.daaam.proceedings. 174

[14] Pandzic, A., Hodzic, D. \& Kadric, E. (2021). Experimental Investigation on Influence of Infill Density on Tensile Mechanical Properties of Different FDM 3D Printed Materials, TEM Journal, Vol. 10, No. 3, DOI: 10.18421/TEM103-25

[15] Cabreria, V. \& Santana R. M. C. (2020). Effect of Infill Pattern in Fused Filament Fabrication (FFF) 3D Printing on Materials Performance, Revista Materia, Vol. 25, No. 3, DOI: 10.1590/S1517-707620200003.1126

[16] Pandzic, A.; Hodzic, D.; Hajro, I. \& Tasic, P. (2020). Strength Properties of PLA Material Obtained By Different Models of FDM 3D Printer, Proceedings of the 31st DAAAM Interational Symposium, pp.0315-0322, B. Katalinic (Ed.), Published by DAAAM International, ISBN 978-3-902734-29-7, ISSN 1726-9679, Vienna, Austria, DOI: 10.2507/31st.daaam.proceedings.044

[17] Valerga, A. P.; Batista, M.; Salguero, J., \& Girot, F. (2018). Influence of PLA filament conditions on characteristics of FDM parts. Materials, Vol. 11, No. 8: 1322, DOI:10.3390/ma11081322 